\title{
Presenteísmo: causas e consequências DE UM MAL SUBTERRÂNEO
}

\section{Presenteeism: causes and consequences of an underground evil}

\section{Giovanna Garrido}

Mestre em Engenharia de Produção. Universidade Federal de São Carlos (UFSCar). Bolsista CNPq do Centro de Tecnologia da Informação Renato Archer. Campinas, SP. Brasil.E-mail: giovanna.garrido@cti.gov.br

\section{Adriana Vazzoler Mendonça}

Especialista em Administração e Gestão da Qualidade - Instituto Nacional de Pós-Graduação (INPG). Pesquisadora Bolsista CNPq do Centro de Tecnologia da Informação Renato Archer. Graduanda em Psicologia na Anhanguera Educacional. Campinas, SP. Brasil. E-mail: adriana.italia@gmail.com

\section{Kelly Marques de Oliveira Lopes}

Mestre em Matemática Aplicada - UNICAMP - IMECC. Pesquisadora Bolsista CNPq do Centro de Tecnologia da Informação Renato Archer. Doutoranda em Matemática Aplicada na Universidade Estadual de Campinas (UNICAMP). Campinas, SP. Brasil.

E-mail: kelly.unesp@yahoo.com.br

\section{Marco Antonio Silveira}

Doutor em Engenharia Mecânica Processos de Fabricação. Faculdade de Engenharia Mecânica - Universidade Estadual de Campinas (UNICAMP). Faculdade de Campo Limpo Paulista - Programa de Pós-Graduação Stricto Sensu em Administração. Centro de Tecnologia da Informação Renato Archer. Campinas, SP. Brasil.E-mail: marco.silveira@cti.gov.br

\section{Resumo}

Este estudo visa construir um mapa sistêmico incluindo as principais variáveis que circundam o construto Presenteísmo, denotando a forma como impactam na produtividade do trabalho e no desempenho das organizações. Classificado como pesquisa bibliográfica de cunho psicológico e sociológico, o estudo sustentou-se em referenciais teóricos disponíveis em periódicos julgados pertinentes à pesquisa. Considerando sua ocorrência na interface entre fatores pessoais e organizacionais, constatou-se que o comportamento presenteísta pode ser determinado por uma propensão individual voluntária ou pela própria irracionalidade da organização. A abordagem sistêmica do presenteísmo mostrou-se útil pelo fato de que, através dela, torna-se possível a compreensão das relações causais e das influências recíprocas, direta ou inversamente proporcionais, entre as variáveis de interesse, oferecendo subsídios para decisões e servindo de orientação para as estratégias de amenização deste fenômeno que ameaça a sustentabilidade organizacional.

Palavras-chave: Presenteísmo, Não-trabalho no trabalho, Desempenho, Produtividade.

\section{Abstract}

This research aims to build a systemic map including the main variables that surround the relation between both phenomena, denoting the way as they impact on job productivity and on organizational performance. It has been classified as a bibliographic research in the psychological and sociological fields, considering journals which are related to the subject. Considering its occurrence on the interface between personal and organizational factors, it was found that the presenteeism can be determined by a voluntary individual propensity or by the organizational irrationality. The graphic approach of the phenomenon was judged pertinent for allowing a comprehensive understanding of the relationship among variables of interest, resulting in guidelines for organizations to take action to reduce and prevent this underground and silent phenomenon, which has been a threat for organizational sustainability.

Key-words: Presenteeism, Non-work at work, Performance, Productivity. 


\section{INTRODUÇÃo}

O presenteísmo tem sido objeto de discussões nos ambientes organizacionais e acadêmicos por impactar negativamente o desempenho das organizações. Porém, esses debates limitam-se a vieses analíticos que o relacionam apenas com aspectos da saúde do trabalhador, alegando ser consequência da inadequação entre a capacidade do indivíduo ao trabalho, em termos físicos e mentais, e a exigência da tarefa.

Contudo, considera-se o presenteísmo como um comportamento que ultrapassa essa esfera. Fundamentando-se em uma perspectiva que o desvenda na apropriação desequilibrada do tempo no trabalho com não-trabalho, este estudo analisa o presenteísmo como algo não relacionado à doença, mas como algo crônico que só se manifesta na empresa.

Nesse contexto, considerando sua ocorrência na interface entre fatores pessoais e organizacionais, o objetivo é construir um mapa sistêmico incluindo as principais variáveis que o circundam, denotando a forma como impactam na produtividade do trabalho e no desempenho das organizações.

Tal metodologia foi julgada pertinente pelo fato de que, através dela, torna-se possível a compreensão das relações causais e das influências recíprocas, direta ou inversamente proporcionais, entre as variáveis de interesse, oferecendo subsídios para decisões e servindo de orientação para as estratégias de amenização desse fenômeno que ameaça a sustentabilidade organizacional.

Para este fim, o artigo estrutura-se da seguinte forma: inicialmente, demonstra-se o método como foi conduzido; depois, apresenta-se o referencial teórico subdividido em cinco tópicos principais. Primeiramente, apresenta-se o conceito. Em seguida, fundamenta-se a questão do não-trabalho no trabalho como viés analítico do comportamento presenteísta, ressaltando a influência de fatores organizacionais $e$ pessoais. O terceiro tópico traz a discussão central do artigo organizando sistemicamente as relações estabelecidas entre os principais fatores que circundam o presenteísmo. No quarto tópico, com vistas a sua utilização como conhecimento aplicado, busca-se traduzir a lógica sistêmica em algumas estratégias de amenização deste fenômeno. No quinto tópico, faz-se alusão ao modelo da Organização Mundial da Saúde (OMS) visando compará-lo ao que é proposto neste estudo em alguns aspectos. Por fim, apresentam-se as conclusões alcançadas no estudo.

\section{Metodologia}

O estudo foi qualitativo, visando abordar o objeto da pesquisa em suas relações sistêmicas.

Assumindo-se como base os quesitos de Gil (2002), o estudo se classifica como exploratório e descritivo. Exploratório, pois, além de se delimitar a um teor analítico que o difere do contingente de publicações acerca do construto presenteísmo e ter um intuito de trabalho diferenciado, específico à construção do mapa sistêmico, a proposta do artigo foi direcionada ao aprimoramento de ideais e à descoberta de intuições concernentes ao comportamento com vistas a torná-lo mais explícito. Descritivo, pois, intui a identificação e a representação das relações entre as variáveis que norteiam o fenômeno com a pretensão de constituir uma nova visão do problema e suas implicações no âmbito organizacional. Para tanto, o estudo foi bibliográfico de cunho psicológico e sociológico, sustentado em referenciais teóricos disponíveis em periódicos julgados pertinentes ao conteúdo e caráter da pesquisa.

Assim, investigaram-se os fundamentos norteadores do comportamento presenteísta no contexto organizacional com o intuito de construir um mapa sistêmico, incluindo as principais variáveis que o circundam, denotando a causalidade entre elas e a forma como impactam na produtividade do trabalho e no desempenho das organizações.

\section{Referencial Teórico}

\subsection{Presenteísmo: uma delimitação do conceito}

No que tange à área do comportamento organizacional, os esforços pela diminuição dos problemas associados ao capital humano tornam-se prioridade. Atenção considerável tem sido direcionada ao absenteísmo e ao presenteísmo. Em virtude de seus impactos para o desempenho econômico e operacional das organizações, para os trabalhadores e para a sociedade, frequentes têm sido os estudos das causas e decorrências concernentes a eles. 
Apesar de se consistir em um fenômeno cujas manifestações vão além daquilo que é percebido $e$ mensurável, constata-se que o presenteísmo se porta como um mal ainda mais pernicioso que o absenteísmo. Mesmo de forma silenciosa, o comportamento presenteísta tem sido considerado um fator de alto custo e forte impacto na produtividade, uma condição negativa ao resultado econômico das organizações (D'ABATE; EDDY, 2007; UMANN; GUIDO; GRAZZIANO, 2012).

Vale dizer que, diferentemente da consistência das considerações de seus impactos na produtividade, observa-se que os debates acerca do fenômeno se limitam a vieses analíticos que o relacionam apenas com aspectos da saúde do trabalhador. Grande parte dos estudos sobre o presenteísmo enviesa a perda de produtividade como algo estritamente relacionado à doença, alegando ser consequência da inadequação entre a capacidade do indivíduo ao trabalho, em termos físicos e mentais, e a exigência da tarefa (BÖCKERMAN; LAUKKANEN, 2009, 2010; COLLINS; CARTWRIGHT, 2012; TALOYAN et al., 2012; UMANN; GUIDO; GRAZZIANO, 2012; UMANN; GUIDO; SILVA, 2014).

Assim, com o intuito de estender o construto para além desta esfera, assume-se a conceituação estabelecida por D'Abate e Eddy (2007) que, combinando a ideia do indivíduo presente e do absenteísmo, definem o presenteísmo como o estar presente no trabalho, mas ausente em mente ou comportamento, de forma que a produtividade seja afetada. Tal escolha se deve à capacidade do enunciado de sintetizar o teor analítico pretendido neste estudo: o presenteísmo como algo que não tem relações com doença, mas como algo crônico que só se manifesta na empresa.

A desconsideração das relações entre o presenteísmo e a saúde do trabalhador direciona a interpretação deste comportamento para um viés analítico que desvenda a ação presenteísta na apropriação desequilibrada do tempo no trabalho com assuntos pessoais, fazendo menção à questão do não-trabalho no trabalho. Afinal, atividades não relacionadas ao trabalho e o desvio no trabalho já se estabelecem como sinônimos do presenteísmo (EDDY; D'ABATE; THURSTON JR, 2010).

\subsection{Não-trabalho no trabalho: uma apropriação silenciosa do tempo}

Sabe-se que os indivíduos gerenciam uma gama de papéis relacionados ao trabalho e ao não-trabalho.
Sua atenção é dividida para o atendimento de três tipos de demanda: trabalho, família e lazer. A questão é que tais demandas não se portam como entidades de gerenciamento individualizadas. Delimitadas por fronteiras permeáveis, muitas das vezes, elas se sobrepõem umas às outras. Assim, mesmo que fisicamente engajado no gerenciamento das demandas de um papel, o indivíduo não é focado e não opera somente para esse fim. É natural que, em mente ou comportamento, ele transponha as fronteiras que o separam dos demais papéis (D'ABATE, 2005; EDDY; D'ABATE; THURSTON JR., 2010; VIJAYAKUMAR, 2015).

Esta convergência entre as demandas da vida pessoal e do trabalho foi propiciada pelo próprio desenvolvimento tecnológico. É fato que, quando se trata de uma sobreposição e não de uma competição entre as demandas, tal ocorrência não seja maléfica. Afinal, o equilibrio entre os vários domínios da vida é importante e possível de ser alcançado (D'ABATE, 2005; IVARSSOM; LARSSOM, 2012; VIJAYAKUMAR, 2015).

O problema reside quando o indivíduo nota um desequilíbrio em seus papéis. São frequentes os casos em que, por interferências internas ou externas, um domínio passa a exercer supremacia e requerer atenção e recursos a ponto de criar conflito perante os demais (VIJAYAKUMAR, 2015). A consequência disso é o desbalanceamento do esforço emocional e da energia requeridos no atendimento das demandas presentes, refletindo no rendimento individual (D'ABATE, 2005).

É a incorporação dos três domínios da vida que sustenta o debate sobre o comportamento presenteísta, alinhando a sua ocorrência ao envolvimento do trabalhador em assuntos não relacionados ao trabalho no trabalho, de modo que se tenha uma apropriação desequilibrada do tempo, do esforço, da inclinação e da energia despendida no atendimento às demandas do trabalho. Daí seu impacto na produtividade (D'ABATE; EDDY, 2007).

\subsubsection{Apropriação do tempo no trabalho: influência de fatores organizacionais e pessoais}

Vale dizer que a apropriação do tempo no trabalho não provém apenas de fatores pessoais, 
muitas vezes, fatores organizacionais induzem essa postura. Seja por questões estruturais, organizacionais e institucionais (PAULSEN, 2015), pelo ambiente organizacional suscetível à postura (EDDY; D'ABATE; THURSTON JR, 2010; PAGE, 2015), ou mesmo por razões mais implícitas, como uma forma de lidar com o estresse (PAGE, 2015), a busca pelo prazer e pelo equilibrio almejado (D'ABATE, 2005; D'ABATE; EDDY, 2007; EDDY; D'ABATE; THURSTON JR, 2010; PAGE, 2015), por insatisfação, por tédio (D'ABATE, 2005; PAGE, 2015; SAARVALA, 2006; VIJAYAKUMAR, 2015), pela tendência a procrastinação (D'ABATE; EDDY, 2007) e pela própria falta de sentido naquilo que é feito (D'ABATE, 2005; PAGE, 2015), o trabalhador passa a estar presente no trabalho, mas ausente em mente, em comportamento, em capacidade para realizar as suas tarefas de forma produtiva e eficaz. Isto é, como um meio de reduzir sua própria frustração $e$ descontentamento $e$ de satisfazer suas necessidades $e$ vícios psicológicos, ele apropria silenciosamente seu tempo em outras coisas, simulando, disfarçando $e$ sabotando a sua própria produtividade (FERREIRA; ESTEVES, 2016; PAULSEN, 2015).

Isso faz da postura presenteísta um dos principais problemas organizacionais relacionados ao capital humano. Porém, é importante notar que ela é consequência da própria noção organizacional que desvaloriza o capital humano. É notória a persistência de sistemas organizacionais que absorvem a personalidade $e$ colonizam a subjetividade, não permitindo nenhuma manifestação de resistência. Isso acaba fazendo com que os indivíduos adotem formas mais sutis de resistência (PAGE, 2015; PAULSEN, 2011), como uma espécie de decaf resistance, assumindo posturas que a simbolizam, mas não testemunham os limites que gera $e$ a violência que a envolve, sendo apenas submersas no silêncio (CONTU, 2008).

Além disso, a ação presenteísta de apropriar o tempo de trabalho em não-trabalho e ter a produtividade prejudicada não se define apenas como uma ação de resistência. Muitas vezes, o indivíduo pode ser forçado à postura pelo próprio desperdício organizado, pela cultura presenteísta que permeia a organização, tendo em vista as explosões de descontentamento entre os trabalhadores, que levam ao tédio e à alienação (PAGE, 2015; PAULSEN, 2011, 2015).

\subsubsection{O presenteísmo na interface entre o significado e a carga do trabalho}

Ao delimitar uma tipologia representativa da apropriação do tempo no trabalho, combinando fatores relacionados à inclinação do indivíduo ao trabalho $e$ fatores relacionados às exigências da tarefa, Paulsen (2015) subsidia o debate acerca da influência de fatores organizacionais e pessoais no presenteísmo.

A interpretação dessa obra permite inferir que, combinando eixos representativos da subjetividade do trabalhador e da objetividade do trabalho, delimitam-se contextos em que o comportamento presenteísta é resultante de fatores pessoais e contextos em que a própria irracionalidade da organização do trabalho o determina, denotando o caráter involuntário deste comportamento. Isto é, quando a opacidade na definição de cargos e tarefas, em termos de suas exigências e da capacidade de seus executores, propicia a conduta presenteísta (PAULSEN, 2011, 2015).

Vale enfatizar que, referindo-se à inclinação individual ao trabalho, Paulsen (2015) afirma que o seu teor não provém da gestão, mas do significado do trabalho. Ou seja, esta inclinação é um fenômeno endógeno que depende da forma como o indivíduo enxerga o trabalho que executa.

Assim, alinhando o debate estabelecido neste estudo aos ideais de Paulsen (2015), estrutura-se a análise do presenteísmo via não-trabalho no trabalho de acordo com o representado na Figura 1, com o fenômeno interfaceando o significado e a carga do trabalho.

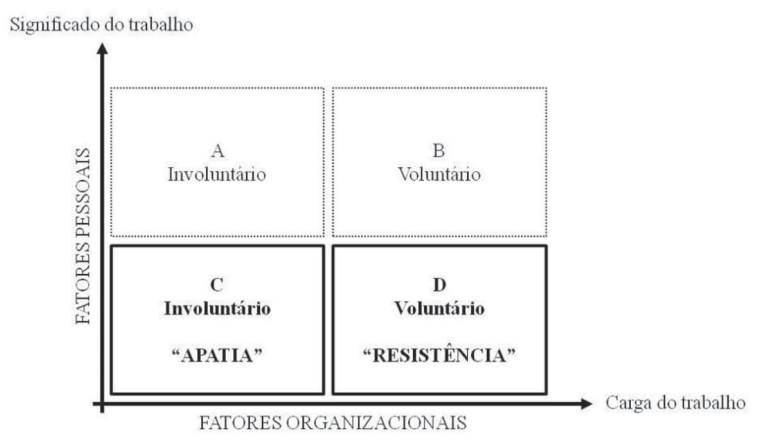

Figura 1 - O estudo do presenteísmo em dois eixos Fonte: Elaboração dos autores.

Observa-se que o comportamento presenteísta pode ser manifesto segundo níveis variáveis de atuação 
de fatores pessoais e organizacionais. Cada quadrante desta tipologia estabelece contextos e razões diferentes para a manifestação deste fenômeno nas organizações.

Porém, conforme é debatido na literatura (EDDY; D'ABATE; THURSTON JR, 2012; FRITZ et al., 2013; FRITZ; LAM; SPREITZER, 2011; PAGE, 2015; PAULSEN, 2011, 2015, entre outros), são fortes as ligações entre o comportamento presenteísta e o significado que o indivíduo atribui ao trabalho, tornando-o mais agudo quanto menor for este significado, como ocorre nos quadrantes $\mathrm{C}$ e D da Figura 1.

Assim sendo, este estudo considera que são estes contextos que mais evocam o sentido de ausência mental e comportamental do conceito de presenteísmo que defende e, por isso, os tem como foco. Afinal, não havendo significado do trabalho, os índices de motivação $e$ atenção são mínimos e maiores são as necessidades do indivíduo de se engajar em outras atividades que lhe façam mais sentido. Consequentemente, são nestes contextos que os impactos do presenteísmo são mais marcantes e a produtividade mais aguçadamente simulada.

Parafraseando Paulsen (2015), o Quadrante C contextualiza a postura presenteísta como involuntária, induzida pelas próprias características do trabalho. Não vendo significado naquilo que desempenha, o fato de exercer uma função cujo nível de estresse não lhe mantém ativo é tratado com indiferença. Assim, o indivíduo se mantém em uma postura inerte e, sem a intenção de mudar, apropria seu tempo em não-trabalho. $\mathrm{Ou}$ seja, na interface destes fatores, a postura presenteísta se manifesta por apatia e desinteresse.

Por sua vez, o Quadrante D contextualiza o presenteísmo como um ato voluntário e manifesto como uma ação de resistência. Sem um relacionamento ético ou identitário com o trabalho, este comportamento se porta como uma racionalização de um trabalho sem sentido, em que o indivíduo usa desequilibradamente seu tempo para estender o período de realização de suas tarefas. Isso mostra que a organização se apresenta como uma arena política permeada por barganhas onde o trabalho tem a opção de silenciar a sabotagem.

De qualquer modo, as motivações para essas apropriações indevidas do tempo no trabalho são diversas. Ora, elas aparecem como um meio de indignação pessoal, ora política, quando implícita à empresa e explícita entre os trabalhadores como uma forma de provocar mudanças, ou mesmo como resultado de algo já introjetado na cultura da empresa. Muitas vezes, pela forma como o trabalho é organizado, a simulação torna-se tão integrada à tarefa que agir de maneira diferente é como um suicídio organizacional, induzindo o resigno passivo como um ajuste ao próprio desperdício (PAULSEN, 2011).

Corroborando a explanação do presenteísmo na interface entre o significado e a carga do trabalho, Paulsen (2011) também pontua que a própria resignação individual em alegar necessidade de tempo livre motiva a postura.

Sabe-se que os indivíduos não se mantêm ativos e engajados em suas atividades todo o expediente. Embora eles difiram entre si pela forma como criam fronteiras entre o trabalho $e$ o não-trabalho, a própria necessidade de sustentação de energias induz microparadas para alívio de fadiga e desconforto físico. Aliás, existem alguns estudos que afirmam que microparadas durante o trabalho são vistas como positivas. Alega-se que o distanciamento mental e psicológico do trabalho, através do envolvimento com outros assuntos, é uma forma de manter ou repor recursos psicológicos considerados limitados, porém importantes para o desempenho (FRITZ et al., 2013; FRITZ; LAM; SPREITZER, 2011).

Desse modo, enfatiza-se que a relação benéfica entre distanciamento mental e psicológico e desempenho no trabalho depende do nível em que ela ocorre. Isto é, níveis muito altos ou baixos de distanciamento são prejudiciais para o desempenho. Assim, é necessária moderação no envolvimento em não-trabalho no trabalho, o suficiente para a recuperação de energias (FRITZ et al., 2013; VIJAYAKUMAR, 2015).

Neste ponto, destaca-se novamente o papel do significado do trabalho nesta tendência presenteísta de apropriação de tempo no trabalho. Quanto maior o significado que o indivíduo atribui ao seu trabalho, menor é a sua necessidade de se desapegar dele para reposição de energias (FRITZ et al., 2013; VITAYAKUMAR, 2015). Considerando o estado afetivo do indivíduo como um recurso para o trabalho, sendo identificado com o que faz, não é o fato de se distanciar mental ou psicologicamente que garantirá seu bem estar e satisfação. O trabalho em si já é uma fonte de prazer (TROUGAKOS; HIDEG, 2009). 
Cruciais para a pretensão deste estudo são os pareceres de Fritz, Lam e Spreitzer (2011) e Trougakos e Hideg (2009) de que é a natureza e o conteúdo do distanciamento mental e psicológico do trabalho que determinam o teor da recuperação de energias e o desempenho individual. Isto é, microparadas no trabalho só são positivas dependendo do tipo de atividades realizadas no momento (FRITZ et al., 2013). Assim, constata-se que envolver-se em não-trabalho como um meio de recuperação de recursos psicológicos não passa de uma falácia. Não-trabalho no trabalho não é associado à manutenção ou reposição de energias.

Trata-se, portanto, de uma estratégia popular $e$ frequente que acaba subsidiando $e$ induzindo o caráter crônico do comportamento presenteísta. Seja por apatia ou como uma manifestação de resistência, a opção por se envolver em não-trabalho no trabalho não retribui ao indivíduo os efeitos desejados, sejam em méritos de reposição de energias ou mesmo de um estado afetivo positivo. Assim sendo, este comportamento torna-se um mal crônico que, atenuando o capital humano, silenciosamente impacta o desempenho organizacional em todos seus aspectos.

\subsection{A postura presenteísta: causas e efeitos sistemicamente representados}

Visando uma representação gráfica do presenteísmo, na Figura 2 é demonstrado um mapa sistêmico que organiza os principais fatores que o circundam, denotando a causalidade estabelecida entre eles e seus efeitos na produtividade do trabalho e no desempenho das organizações.

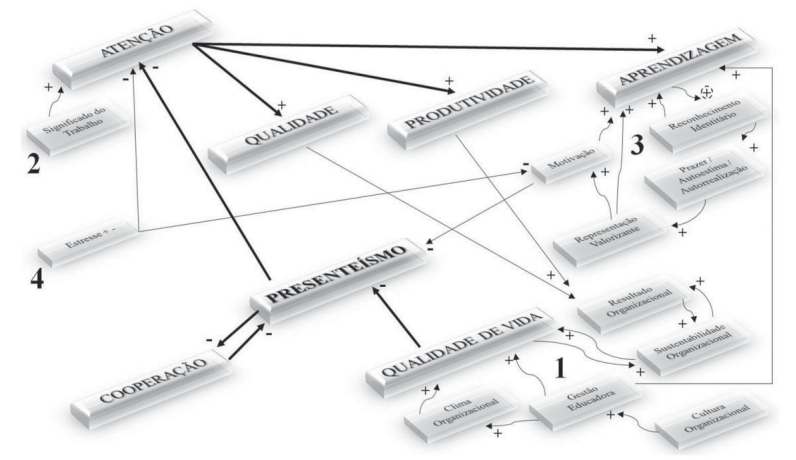

Figura 2 - Mapa sistêmico

Fonte: Criação dos autores

Observa-se que a Figura é composta por um mapa principal, representado por blocos e flechas espessos, que consolida os seis principais fatores relacionados com a variável Presenteísmo, a saber: Qualidade de Vida, Cooperação, Atenção, Qualidade, Produtividade e Aprendizagem. Agregados a ele, tem-se quatro submapas que também devem ser considerados na interpretação e gestão do fenômeno. Numerados de 1 a 4 e representados por blocos e flechas tênues, eles constituem o segundo plano do mapa sistêmico e atuam em perspectiva garantindo a sustentação dos fatores principais na relação com o presenteísmo.

$\mathrm{O}$ fundamento de tal representação, assim como de todos os mapas sistêmicos, tem como base hipóteses, intuições e o próprio conhecimento especializado acerca das relações recíprocas estabelecidas entre os fatores. Vale a explicação de que as relações expostas são diretamente proporcionais, quando representadas com o sinal (+), e inversamente proporcionais, quando representadas com o sinal (-).

Assim, o mapa representa uma sumarização das questões discutidas a respeito do comportamento presenteísta a partir de sua acepção de não-trabalho no trabalho. Concernentes a sua posição no mapa principal, observa-se que o comportamento tem como antecedentes principais a Qualidade de Vida e a Cooperação.

A relação inversamente proporcional entre Presenteísmo e Qualidade de Vida explicita que a apropriação desequilibrada do tempo no trabalho se deve à presença de elementos estressores e a outros indicadores físicos e psicológicos de bem estar (VIJAYAKUMAR, 2015).

Nota-se que esta relação é sustentada por subfatores organizacionais (Submapa 1) provenientes da própria Cultura Organizacional. Muitas vezes, como consequência do contexto em que se insere, a organização acaba propiciando condições para o comportamento presenteísta. Inclusive, a maneira como a gestão se estabelece é correlata à manifestação do comportamento. É por este motivo que se pontua o papel da Gestão Educadora e sua influência direta sobre o comportamento e suas consequências. Modelos de gestão que prezam o relacionamento com o trabalhador, além de influentes na constituição do Clima Organizacional, tendem a reduzir a exaustão emocional (FERREIRA et al., 2015) e a propensão individual ao envolvimento em não-trabalho no trabalho. 
A Cooperação também consiste em um fator inversamente relacionado ao Presenteísmo. Pela sua influência no estresse e na consequente alteração de humor e desmotivação, a falta de atitudes cooperativas se estabelece como razão do comportamento presenteísta (SAARVALA, 2006). A qualidade do relacionamento e da cooperação no trabalho atua na reposição dos recursos psicológicos e quanto mais energizado física $e$ psicologicamente, menor é a propensão individual em ausentar-se do trabalho em mente ou comportamento e apropriar o tempo em não-trabalho (FRITZ; LAM; SPREITZER, 2011).

Nota-se que a relação entre Cooperação e Presenteísmo é biunívoca. Assim, a apropriação do tempo no trabalho com não-trabalho também impacta nas atitudes cooperativas e no relacionamento interpessoal. Mesmo que presente, o distanciamento mental e comportamental e a falta de foco no trabalho impossibilitam o gerenciamento das demandas e atitudes concernentes a ele.

Já os efeitos do Presenteísmo no Resultado Organizacional são delimitados pelo seu impacto no índice de Atenção individual, fator diretamente relacionado com a Produtividade, Qualidade e Aprendizagem. Isto é, pelos lapsos de atenção, o presenteísmo limita o desempenho em quantidade, pela diminuição do rendimento físico e mental, em qualidade, pela possibilidade de erros no desenvolvimento das atividades laborais (UMANN; GUIDO; GRAZZIANO, 2012) e em méritos de capacitação, visto que, estando engajado em não-trabalho, menor é o tempo despendido pelo indivíduo no desenvolvimento de novos conhecimentos e habilidades. Como visto, a falta de atenção é o que dificulta o desempenho eficiente e eficaz no trabalho (D'ABATE e EDDY, 2007).

Corroborando o foco deste estudo, o índice de Atenção é subsidiado pelo Significado do Trabalho de maneira diretamente proporcional (Submapa 2). Isso comprova que a delimitação do impacto do comportamento presenteísta na eficiência e eficácia do trabalho $e$, consequentemente, no Resultado Organizacional, é atrelado ao quanto ele é significativo àquele que o executa.

A referência à Aprendizagem como uma limitação do presenteísmo deve-se, também, a sua influência na Motivação, um fator essencial que subsidia a consideração do aprendizado como estratégia de melhoria do desempenho. Tratando-se de um estado psicológico do qual provêm os motivos $e$ a determinação para cada ação humana, a Motivação engloba o interesse e o comprometimento afetivo com o trabalho e com o aprendizado (GODOI; FREITAS; CARVALHO, 2011; KIKUCHI; SALES; TARRAGÔ, 2013).

Inclusive, é válido ressaltar que esta relação é garantida quando se considera o Significado do Trabalho e a própria essência humana como fatores influentes. Afinal, a associação entre a subjetividade do indivíduo com a ação que pratica só é permitida por meio da análise da relação entre o trabalho $e$ a vida deste indivíduo (DEJOURS, 2004).

É diante desta influência que ocorre o desencadeamento de reações que subsidiam a relação entre a Aprendizagem e Motivação (Submapa 3). Objetivamente, sabe-se que, considerando o trabalho como fonte de significação e elemento de identificação pessoal, o fato de enriquecê-lo cognitivamente soa para o indivíduo como uma ação de Reconhecimento Identitário. Isto é, o aprendizado atua como um elemento que reforça seu conceito e reconhece sua essência humana (MORETTI e TREICHEL, 2003; SILVEIRA; MAIA; FIORAVANTI, 2012).

Pela satisfação das necessidades concernentes a sua natureza e da saciedade de suas demandas intrínsecas pelo desenvolvimento de competências, o fato de estar inserido em um processo de aprendizagem floresce o reconhecimento que o indivíduo tem de sua imagem e de si mesmo, influenciando sua Autoestima, Autorrealização e Prazer com aquilo que faz (GODOI; FREITAS; CARVALHO, 2011).

Posto que o enriquecimento cognitivo e a atribuição de mais sentido naquilo que faz remetem a uma valorização daquilo que o indivíduo realmente é, suas próprias funções cognitivas o direcionam a um estado de Representação Valorizante, um estado de satisfação pelo favorecimento de suas necessidades humanas. Vale dizer que, de forma consequente a este estado emocional, as próprias atitudes que cuidam da aprendizagem são conjugadas e a subjetividade do indivíduo o permite investir no aperfeiçoamento de suas competências performáticas Assim, o desenvolvimento das potencialidades humanas é aprimorado, redundando em maior compromisso e produtividade (FONSECA, 2014; TÉLLEZ, 2012).

Considera-se que, uma vez que a Aprendizagem floresce a Representação Valorizante do indivíduo e as 
emoções humanas permitem que as ações inerentes ao processo sejam conjugadas, a subjetividade do indivíduo é enriquecida e ele acaba sendo conduzido a um estado de motivação intrínseca (FONSECA, 2014), uma manifestação do processo de aprendizagem na subjetividade humana que atua na propensão individual em tirar vantagens da oportunidade para aplicação dos conhecimentos adquiridos (WEISSBEIN et al., 2011).

Observa-se que, assim como as variáveis Reconhecimento Identitário e Representação Valorizante, a Motivação também se posiciona como um fator que alimenta a aprendizagem e o desenvolvimento cognitivo, levando em consideração o estado emocional do indivíduo e a afetividade requerida por esse estado (KIKUCHI; SALES; TARRAGÔ, 2013)

Sendo assim, o intuito da representação destes efeitos é relatar a forma como a limitação mental ou comportamental à Aprendizagem impacta no processo motivacional, fortalecendo ainda mais o comportamento presenteísta e prejudicando o desempenho no trabalho. Afinal, sendo a Motivação um processo psicológico responsável pelo teor de esforço para o alcance dos resultados (KIKUCHI; SALES; TARRAGÔ, 2013), postula-se que quanto menor a motivação de um indivíduo, maior sua propensão ao Presenteísmo.

Influente na Motivação também é a carga de trabalho, representada pela variável Estresse (Submapa 4). Uma carga de trabalho que faz com que o trabalhador opere em um nível de estresse superior ou inferior ao seu nível ótimo, além de impactar nos níveis de Atenção, tende a gerar desmotivação e irritabilidade (SAARVALA, 2006), propiciando condições para a apropriação do tempo no trabalho com não-trabalho.

Em suma, comprova-se a opinião de Böckerman e Laukkanen (2010) de que o presenteísmo tem como determinantes tanto as características do trabalhador como do trabalho. Isto é, sob influência de fatores pessoais e organizacionais, tem-se um comportamento que, subterraneamente, ameaça a Sustentabilidade Organizacional. Sabendo-se que o conceito se resume na combinação entre Qualidade de Vida e Resultado Organizacional (SILVEIRA e BECARO, 2014), corrompida esta combinação, silenciosos e cruéis são seus efeitos no âmbito organizacional.

\subsection{Amenizando o inevitável: alternativas para ação da gestão}

Sabendo que ignorar as conexões entre o trabalho e o não-trabalho incorre em custos e perdas na produtividade, cabe à organização reconhecê-las e atuar na interface que as delimitam (D'ABATE, 2005). Assim, faz-se necessário explorar algumas estratégias de atuação da gestão para amenizar os efeitos deste mal que silenciosamente impacta o desempenho das organizações.

$\mathrm{Na}$ atual realidade econômica, existem diversas alternativas de atuação (FRITZ; LAM; SPREITZER, 2011). No entanto, o que prevalece são pontos de vista que priorizam a adoção de políticas de intervenção para deter e eliminar a ocorrência deste comportamento (EDDY; D'ABATE; THURSTON JR, 2010). Isto é, alternativas de ação que consideram apenas os fatores organizacionais que o impactam. Tais medidas, além do alto custo, são de difícil adaptação a cada caso.

Assim, tratando-se de um fenômeno relacionado ao capital humano, são requeridas maneiras mais informais de atuação (D'ABATE, 2005), ou um delineamento estratégico que também considere os fatores intrínsecos impactantes neste tipo de comportamento (FRITZ; LAM; SPREITZER, 2011).

A justificativa para este parecer está na própria defesa da proximidade entre a postura presenteísta e o significado que o indivíduo atribui ao trabalho, estabelecida no tópico 3.2.2. Sabe-se que o significado do trabalho não é determinado apenas por fatores extrínsecos concernentes ao contexto organizacional, mas por fatores intrínsecos que os qualificam.

Desse modo, uma vez que a apropriação do tempo em assuntos pessoais é inevitável e o ato de trabalhar não necessariamente inclua o trabalho (D'ABATE e EDDY, 2007; PAULSEN, 2015), toda e qualquer ação organizacional não deve se limitar à objetividade ou à subjetividade subjacentes. Para que o tempo e a atenção dedicados a essas atividades sejam os menores possíveis, a organização deve atuar simultaneamente nos dois âmbitos.

Referir-se à adoção de estratégias simultâneas é remeter-se à tipologia exposta na Figura 1 e enfatizar que a propensão ao envolvimento em não-trabalho no trabalho pode ser amenizada por meio de medidas que abranjam tanto a questão do significado como da carga do trabalho. 
Sustentando esse ponto de vista, ressalta-se o parecer de Eddy, D'Abate e Thurston $\mathrm{Jr}$ (2010) de que atuar estrategicamente na reversão desse fenômeno é tornar o trabalho mais significativo e atentar-se às características das tarefas de acordo com as características dos trabalhadores, de modo que não estimulem o indivíduo à sabotagem, aos lapsos de atenção ou a qualquer outro tipo de comportamento não produtivo.

Ciente da dificuldade de atuação direta nos fatores intrínsecos dos trabalhadores, no que tangem às questões acerca do significado do trabalho, destaca-se a adoção de medidas estratégicas para ampliação do repertório cognitivo e aprendizagem, oportunizando mudanças nas crenças e valores individuais e permitindo novas escolhas e novos comportamentos.

Já em relação à objetividade do trabalho, aqui representadas por fatores relacionados à carga do trabalho, destaca-se o papel das metas e métricas bem definidas e a criação de indicadores de produtividade, com vistas a manter os trabalhadores em sua produtividade ótima, reduzindo as oportunidades de engajamento em não-trabalho no trabalho.

Conforme abordado anteriormente, existe uma predominância no pensamento organizacional em relação às atuações objetivas. Porém, sem que haja sentido naquilo que é exercido no trabalho, metas e métricas envolvem o indivíduo nas demandas do trabalho, mas não necessariamente o direcionam ao sentimento de prazer naquilo que faz. O cumprimento de suas obrigações o conduz a um estado intermediário de satisfação, visto que o indivíduo sabe que suas ações não deixaram de ser atos simulados e não representaram o seu potencial. Essa não satisfação pode levar ao tédio, induzindo o caráter crônico da postura presenteísta.

Assim, com a adoção de estratégias simultâneas nos dois eixos da tipologia, as demandas do trabalho tornam-se primordiais para o indivíduo e ele, mais engajado, desfruta do prazer daquilo que faz. Havendo prazer, menores são as chances de não-trabalho no trabalho.

Tendo em vista a consonância do que propõem à abordagem defendida neste estudo, é válido referenciar mais uma vez Fritz, Lam e Spreitzer (2011). Alinhando-se à consideração de que a postura presenteísta pode ser decorrente da resignação individual em alegar necessidade de tempo livre para reposição de recursos psicológicos, reforçam-se três fatores abordados que se portam como pilares de ação estratégica para amenização deste comportamento: Aprendizagem, Relacionamento e Significado do Trabalho.

A consideração da aprendizagem como elemento estratégico explica-se pelo fato de que a própria noção de crescimento e desenvolvimento propicia o florescimento dos recursos psicológicos necessários ao trabalho, o que faz com que o indivíduo não se veja diante da necessidade de distanciamento mental e psicológico para reposição de suas energias. Além disso, cada vez que seu estado mental o permite investir no aperfeiçoamento de suas competências performáticas e ser mais orientado ao aprendizado, o indivíduo torna-se aberto para o novo e os sinais de apatia e resistência tornam-se cada vez mais amenos e menos influentes no comportamento que assumem (FRITZ; LAM; SPREITZER, 2011).

Vale também enfatizar que, sendo um processo que exige ação e reflexão contínuas para se auferir resultados, ao mesmo tempo em que aprimora as competências individuais, o aprendizado tem potencial de enriquecer as práticas organizacionais, fazendo dele um elemento de transformação tanto no âmbito dos fatores pessoais como no âmbito dos fatores organizacionais.

Da mesma forma, os relacionamentos positivos também são responsáveis pela energização do indivíduo tanto física quanto psicologicamente, visto que é inerente à essência humana o demandar por qualidades pessoais e relacionais (SANT'ANNA; MORAES; KILIMNIK, 2005). Considera-se que a falta de relacionamentos absorve os recursos psicológicos, afetando a qualidade do relacionamento interpessoal e a cooperação no trabalho. Consequentemente, o indivíduo fica propenso à apropriação desequilibrada do seu tempo com não-trabalho. Neste pilar estratégico, Fritz, Lam e Spreitzer (2011) enfatizam que o relacionamento que mais garante vigor no trabalho e ameniza o não-trabalho no trabalho é o relacionamento com a gestão.

Ciente de que a propensão ao comportamento presenteísta é mais aguda quando o trabalho não é visto como significativo, atentar-se às questões envoltas ao significado do trabalho também consiste em uma ação estratégica para amenizar este mal. Conforme abordado, quanto mais o indivíduo percebe que suas tarefas e metas são significantes, menor é a sua propensão e necessidade de se envolver com não-trabalho (FRITZ; LAM; SPREITZER, 2011). 
Observa-se que, centrada nesses três aspectos, a proposta de Fritz, Lam e Spreitzer (2011) justifica a delimitação do estudo do presenteísmo aos dois contextos em que o estar presente no trabalho, mas ausente em mente ou comportamento, relaciona-se à falta de sentido naquilo que é desempenhado (Figura 1). Tendo em mente tal tipologia, esses fatores se mostram como alternativas válidas dentre as estratégias a serem tomadas para amenizar o fenômeno.

Com base na Figura 2, alinhando-se a esses aspectos, a organização estará atuando diretamente nos principais fundamentos do mapa. Objetivamente, o aprender faz o indivíduo mais motivado ao seu trabalho $e$, consequentemente, menos propenso à postura presenteísta. O relacionamento, além de propiciar a cooperação entre os trabalhadores e, quando estreitado com a gestão, promover melhorias na qualidade de vida no trabalho, consiste em um fator essencial ao próprio aprendizado. Por sua vez, um trabalho significativo eleva o nível de atenção individual e a propensão ao processo de aprendizado, remetendo a todos os efeitos já discutidos. Como se nota, a sua importância reforça a dos outros dois fatores.

Assim, unindo a essencialidade dos três pilares estratégicos de Fritz, Lam e Spreitzer (2011), destaca-se o papel da gestão educadora. Sabe-se que, na coordenação do capital intelectual, o gestor educador é aquele que, sem comprometer a sua capacidade de gerenciar, é o responsável em relacionar-se com o trabalhador e identificar as competências a serem desenvolvidas, considerando a sua função e o seu perfil, de forma que a aprendizagem seja não homogênea, mas dotada de sentido (SILVEIRA; MAIA; FIORAVANTI, 2012).

Tratando-se de um estilo gerencial que age estrategicamente na interface entre a Aprendizagem, Relacionamento e Significado do Trabalho, pode-se dizer que o aprimoramento da gestão neste aspecto também se alinha às alternativas para o combate do presenteísmo por não-trabalho no trabalho. A amenização deste comportamento requer que a gestão conheça as tendências individuais (FRITZ et al., 2013). É conhecendo os trabalhadores que a organização se torna capaz de gerenciá-los e de delinear as barreiras entre o trabalho e a vida pessoal (EDDY; D'ABATE; THURSTON JR, 2010).

Utilizando-se uma estratégia de aproximação individualizada, torna-se possível desvendar o senti- mento subjacente ao trabalho executado. Conhecer cada trabalhador individualmente é o fundamento para que a gestão educadora possa descobrir aquilo que compõe sua identidade, que sentido ele remete às suas atividades, como ele se sente no trabalho e quais são as suas necessidades e aspirações.

Ciente de que o indivíduo é movido à satisfação de suas necessidades (SAARVALA, 2006), o entendimento, gerenciamento e acompanhando do trabalhador, de suas demandas e de seus possíveis conflitos de interesse, subsidiam medidas efetivas na atuação sobre o desequilíbrio na apropriação do tempo no trabalho (D'ABATE e EDDY, 2007).

Relacionando-se com o trabalhador, a gestão educadora tem meios para fazer com que cresça em suas funções o significado psicológico, adotando medidas de estímulo cognitivo que acabam fazendo com que ele sinta sua identidade reconhecida e suas necessidades satisfeitas.

Pelo fato de cada sujeito apresentar uma propensão individualizada em cada um dos fatores indutores da atitude presenteísta, a precisão na atuação da organização sobre o presenteísmo está na capacidade de reconhecer padrões de comportamento e suas alterações, possibilitando abordar cada situação conforme suas especificidades e características dos manifestantes.

Inclusive, é por meio do relacionamento que se torna possível o gerenciamento do estresse de cada trabalhador. Ou seja, é relacionando-se com o trabalhador que a gestão detém meios de prover estímulos ao trabalho, favorecendo acesso a um nível ótimo de estresse que o mantém motivado, energizado e engajado em suas atividades (SAARVALA, 2006).

Remetendo à aprendizagem, é o relacionamento que permite a preparação do indivíduo para o aprendizado e para a transferência do conhecimento após o processo (WEISSBEIN et al., 2011). É conhecendo o trabalhador e relacionando-se com ele que a gestão educadora consegue identificar quais os tipos de competências que lhe dão prazer e quais não dão prazer a esse indivíduo. Muitos gestores falham em desenvolver competências, considerando apenas os resultados em curto prazo, não sabendo que tais conhecimentos, habilidades ou atitudes podem não sustentar o prazer do indivíduo no longo prazo (TANURE, 2008), fazendo da ação organizacional sobre o comportamento presenteísta algo temporário e efêmero. 
Em suma, a postura presenteísta, manifestada de forma voluntária ou involuntária, é amenizada quando há harmonia entre as metas organizacionais $e$ as necessidades dos indivíduos. A harmonização dos interesses é uma forma em que a organização cooperativamente gerencia as responsabilidades e demandas da vida pessoal $e$, consequentemente, a propensão ao transbordamento desses fatores no dia-a-dia do trabalho (D'ABATE; EDDY, 2007; SAARVALA, 2006).

Estratégias desse tipo podem não ser palatáveis para as organizações, alegando-se a impossibilidade de intervir nos fatores intrínsecos. Porém, nenhuma norma ou procedimento é requerido. A atuação em melhorias no ambiente e no relacionamento entre a gestão $e$ os trabalhadores mostra-se mais efetiva do que qualquer política contra o comportamento presenteísta (EDDY; D'ABATE; THURSTON JR, 2010).

\subsection{Alusão ao modelo da Organização Mundial da Saúde}

Os esforços pelo entendimento dos problemas associados ao capital humano têm sido objeto de atenção de diferentes áreas do conhecimento. Associando a sua ocorrência a fatores psicossociais, torna-se comum atribuí-los à baixa qualidade de vida, segurança $e$ saúde no trabalho.

Visando o tratamento desses aspectos, a Organização Mundial da Saúde - OMS adota o modelo Psychological Risk Management - Excellence Framework - PRIMA-EF (Figura 3), que elege o estresse como a principal variável da qualidade de vida no trabalho $e$ o presenteísmo como um dos seus resultados, na concepção de estar presente no trabalho mesmo estando adoecido ou com algum sofrimento (PRIMA-EF, 2011).

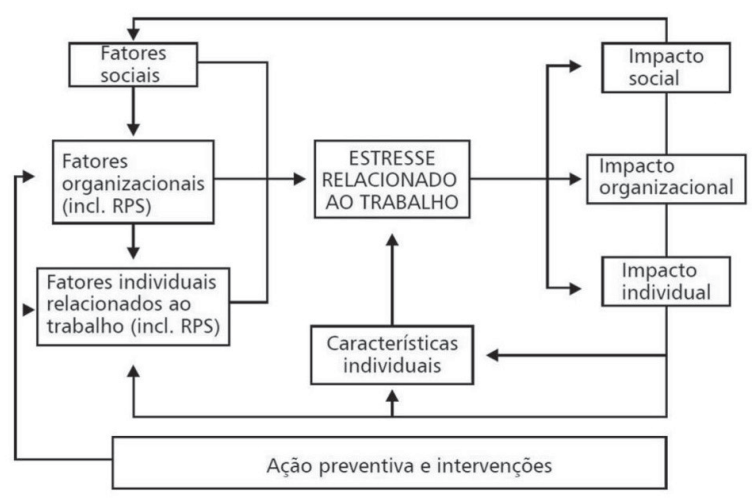

Figura 3 - Modelo OMS/PRIMA-EF (RPS = Riscos Psicossociais)

Fonte: PRIMA-EF, 2011, p. 25
Visando comparar alguns aspectos deste modelo ao que é proposto neste estudo, observa-se que a OMS/ PRIMA-EF, como um representante do contingente de pesquisas que atrela o presenteísmo aos aspectos da saúde do trabalhador, apresenta um cenário genérico de influências e posiciona o estresse como epicentro que origina o comportamento e seus respectivos impactos.

Já o modelo proposto, apresentando uma visão minuciosa das causas e efeitos do presenteísmo, posiciona o estresse como uma das variáveis impactantes deste comportamento e explicita outras também influentes. Aliás, a própria relação entre o estresse e o presenteísmo se dá por meio de uma concepção diferente. Embora também considere as características individuais, pelo desvínculo do estudo aos aspectos da saúde atrelou-se o estresse à carga de trabalho. No comparativo entre a carga de trabalho e a capacidade produtiva do trabalhador, trabalhar com nível de estresse abaixo ou acima do necessário para a mobilização das potencialidades é prejudicial e favorece o não-trabalho no trabalho.

Tendo como base a abordagem do presenteísmo na interface entre fatores pessoais e organizacionais ( $\mathrm{Fi}$ gura 1), os pontos de ações preventivas estabelecidos pela OMS são consonantes aos ideais deste estudo, diferindo-se, contudo, nas estratégias adotadas.

Assim, constata-se que a dissonância entre o modelo da OMS e o proposto reside em três fatores: a etiologia do presenteísmo, a consequente generalização da influência do estresse e as estratégias adotadas para amenização do comportamento.

\section{Considerações Finais}

O objetivo deste artigo foi construir um mapa sistêmico incluindo as principais variáveis que circundam o construto Presenteísmo, denotando a forma como impactam na produtividade do trabalho e no desempenho das organizações. Para tanto, realizou-se um estudo bibliográfico, de caráter exploratório e descritivo, visando fundamentar tal construção.

Com a realização do estudo é possível afirmar que as análises predominantes acerca do presenteísmo limitam-se a relacioná-lo apenas aos aspectos da saúde do trabalhador. Assim, sua relevância reside no caráter diferenciado da reflexão que promove, analisando-o 
como algo não relacionado à doença, mas como algo crônico que só se manifesta na empresa.

Nesse contexto, estruturou-se a análise do presenteísmo a partir de sua acepção de não-trabalho no trabalho, relacionando a sua manifestação ao uso desequilibrado do tempo no trabalho com aquilo que não é relacionado ao trabalho, daí seu impacto na produtividade. Assim, considerando sua ocorrência na interface entre fatores pessoais e organizacionais, constatou-se que o comportamento presenteísta pode ser determinado por uma propensão individual voluntária ou pela própria irracionalidade da organização.

A solidez deste debate foi garantida ancorando-o a dois eixos representativos da subjetividade do trabalhador e da objetividade do trabalho: o significado do trabalho e a carga do trabalho. O estudo considerou que o presenteísmo ocorre segundo níveis variáveis de atuação destes fatores. Contudo, ressalta-se que esse comportamento se torna mais agudo quanto menor for o significado que o indivíduo atribui ao trabalho, contexto que mais evoca o sentido de ausência mental e comportamental do conceito de presenteísmo que defende.

Em suma, a metodologia sistêmica empregada foi pertinente pelo fato de permitir a compreensão das relações causais e das influências recíprocas, direta ou inversamente proporcionais, entre as variáveis de interesse, oferecendo subsídios para decisões e servindo de orientação para as estratégias de amenização deste mal que ameaça a sustentabilidade organizacional.

Há de se considerar que este artigo pode ser subsídio para novos estudos. O mapa sistêmico, com suas variáveis direta ou inversamente relacionadas, sugere sistemas de medição para essas grandezas no contexto organizacional onde a produção realmente ocorre. Além disso, diante de tantas variáveis subordinadas à subjetividade humana, sugere-se sua exploração por meio de lógicas matemáticas, como a Lógica Fuzzy, propiciando diferentes combinações entre as variáveis elencadas.

Ainda, a abordagem ao presenteísmo limitou-se à questão do não-trabalho no trabalho, em especial a sua manifestação por razões circundas aos contextos $\mathrm{C}$ e D da Figura 1. Deste modo, uma recomendação válida seria a realização de um estudo comparativo tendo como base os quadrantes $\mathrm{A}$ e $\mathrm{B}$.
Além disso, centrando-se nesse enfoque, não foram consideradas outras possíveis abordagens capazes de também contribuir com novos lampejos acerca do comportamento, abrindo-se, portanto, possibilidades de novas reflexões sobre o construto.

\section{AgradeCiMENTOS}

Ao Grupo de Apoio à Inovação e Aprendizagem do Centro de Tecnologia da Informação Renato Archer (GAIA-CTI).

\section{REFERÊNCIAS}

BÖCKERMAN, P.; LAUKKANEN, E. Predictors of sickness absence and presenteeism: does the pattern differ by a respondent's health? Journal of Occupational and Environmental Medicine, v.52, n.3, p. 332-335, 2010. What makes you work while you are sick? Evidence from a survey of workers. European Journal of Public Health, v.20, n.1, p. 43-46, 2009.

COLLINS, A.; CARTWRIGHT, S. Why come into work ill? Individual and organizational factor underlying presenteeism. Employee Relation, v.34, n.4, p.429-442, 2012.

CONTU, A. Decaf resistance on misbehavior, cynicism, and desire in liberal workplaces. Management

Communication Quarterly, v.21, n.3, p. 364-379, 2008.

D'ABATE, C. P. Working hard or hardly working: a study of individuals engaging in personal business on the job.

Human Relations, v.58, n.8, p. 1009-1032, 2005.

D'ABATE, C. P.; EDDY, E. R. Engaging in personal business on the job: extending the presenteeism construct. Human Resource Development Quarterly, v.18, n.3, p. 361-383, 2007.

DEJOURS, C. Subjetividade, trabalho, ação. Revista

Produção, v.14, n.3, p. 27-34, 2004.

EDDY, E. R.; D'ABATE, C. P.; THURSTON JR, P.W.

Explaining engagement in personal activities on company time. Personnel Review, v.39, n.5, p. 639-354, 2010. 
FERREIRA, A. I. et al. LMX as a negative predictor of presenteeism climate: a cross-cultural study in the financial and health sectors. Journal of Organizational Effectiveness: People and Performance, v.2, n.3, p. 282-302, 2015.

FERREIRA, A. I.; ESTEVES, J. D. Perceptions of time at work. Personnel Review, v.45, n.1, p. 29-50, 2016.

FONSECA, V. da. Papel das funções cognitivas, conativas e executivas na aprendizagem: uma abordagem neuro psicopedagógica. Revista Psicopedagogia, v.31, n.36, p. 236-253, 2014.

FRITZ, C. et al. Embracing work breaks: recovering from work stress. Organizational Dynamics, v.42, p. 274-280, 2013.

FRITZ, C.; LAM, C. F.; SPREITZER, G. M. It's the little things that matter: an examination of knowledge workers' energy management. The Academy of Management Perspectives, v.25, n.3, p. 28-39, 2011.

GIL, A. C. Como elaborar projetos de pesquisa. 4. ed. São Paulo: Atlas, 2002.

GODOI, C. K.; FREITAS, S. M. F. de.; CARVALHO, T. B. Motivação na aprendizagem organizacional: construindo as categorias afetiva, cognitiva e social. Revista de Administração Mackenzie, v.12, n.2, p. 30-54, 2011.

IVARSSON, L.; LARSSOM, P. Personal activities on company time to make everyday life work. In: BERGMAN, A.; HUZELL, B. Segregationens seghet och dess föränderliga former. Karlstad, Sweden: Universitetstryckeriet, 2012. p. 127-137.

KIKUCHI, L. S.; SALES, E. A.; TARRAGÔ, R. M. Enriquecimento cognitivo para desenvolvimento da inovação e do potencial humano. In: SILVEIRA, M. A. et al. Inovação para desenvolvimento de organizações sustentáveis. Campinas, SP: CTI (Centro de Tecnologia da Informação Renato Archer), p. 31-43, 2013.

MORETTI, S.; TREICHEL, A. Qualidade de vida no trabalho x auto-realização humana. Revista Leonardo pós-Órgão de Divulgação Científica e Cultural do ICPG, Blumenau, v.1, n.3, p. 73-80, 2003.
PAGE, D. Teacher's personal web use at work. Behavior \& Information Technology, v.34, n.5, p. 443-453, 2015.

PAULSEN, R. Layers of dissent: the meaning of time appropriation. Outlines. Critical Practice Studies, v.13, n.1, p. 53-81, 2011.

Non-work at work: resistance or what?

Organization, v.22, n.3, p. 351-367, 2015.

PRIMA-EF. Orientações do modelo europeu para a gestão de riscos psicossociais: um recurso para empregadores $e$ representantes dos trabalhadores. Tradução do Serviço Social da Indústria Departamento Nacional. Brasília: SESI, 2011. $63 \mathrm{p}$.

SAARVALA, E. Presenteeism: the latest attack on economic and human productivity. Human Resources Management, 2006.

SANT'ANNA, A. de S.; MORAES, L. R. F. de; KILIMNIK, Z. M. Competências individuais, modernidade organizacional e satisfação no trabalho: um estudo de diagnóstico comparativo. RAE - Eletrônica, v.4, n.1, 2005. Disponível em < http://bit.ly/2zJLMul> . Acesso em 24 out. 2017.

SILVEIRA, M. A., BECARO, T. C. Competitividade com qualidade de vida: estratégias e práticas baseadas na valorização do fator humano nas organizações. In: SILVEIRA, M. A; BECARO, T. C. (Orgs.).

Competitividade com qualidade de vida: o capital humano como fator de produção. Campinas, SP: CTI (Centro de Tecnologia da Informação Renato Archer), p. 21-37, 2014.

SILVEIRA, M. A.; MAIA, L.; FIORAVANTI, M.

Aprendizagem organizacional para a sustentabilidade: integração ao trabalho e valorização do fator humano. In: SILVEIRA, M. A. Gestão da sustentabilidade organizacional: inovação, aprendizagem e capital humano. Campinas, SP: CTI (Centro de Tecnologia da Informação Renato Archer), p. 163-180, 2012.

TALOYAN, M. et al. Sickness presenteeism predicts suboptimal self-rated health and sickness absence: a nationally representative study of the Swedish working population. PLOS ONE, v.7, n.9, 2012. Disponível em < http://bit.ly/1QO6kBh>. Acesso em 02 mai. 2016. 
TANURE, B. Sofrimento transitivo. GVexecutivo, v.7, n.6, p. 62-67, 2008.

TÉLLEZ, J. A. V. Implicaciones de la teoría motivacional de la autodeterminación en el ámbito laboral. Revista Electrónica Nova Scientia, v.5, n.9, p. 154-175, 2012. Disponível em: < http://bit.ly/1Oa5wvW> . Acesso em: 17 dez. 2015.

TROUGAKOS, J. P.; HIDEG, I. Momentary work recovery: the role of within-day work breaks. Current perspectives on job-stress recovery: research in occupational stress and well being, v.7, p. 37-84, 2009.

UMANN, J.; GUIDO, L. de A.; GRAZZIANO, E. da S. Presenteísmo em enfermeiros hospitalares. Rev. LatinoAm. Enfermagem, Ribeirão Preto, v.20, n.1, p. 159-166, 2012.

UMANN, J.; GUIDO, L. de A.; SILVA, R. M. da. Estresse, coping, e presenteísmo em enfermeiros que assistem pacientes críticos e potencialmente críticos. Rev Esc Enferm USP, São Paulo, v.48, n.5, p. 891-898, 2014. Disponível em: <http://bit.ly/1rejXVz>. Acesso em: 02 mai. 2016.

VIJAYAKUMAR, P. B. Work-life balance, identity salience and break taking behaviors in Indian expatriates. 2015, 83p. Dissertação (Master of Science: Psychology), The University of Tennessee at Chattanooga. Chattanooga, Tennessee, 2015.

WEISSBEIN, D. A. et al. Influencing learning states to enhance trainee motivation and improve training transfer. Journal of Business and Psychology, v.26, p. 423-435, 2011. 